\title{
Wireless Wearable Smart Healthcare Monitoring using Android
}

\author{
Manasa \\ Sri Jayachamarajendra College of Engineering, Department of ECE, Mysuru, 570006, India \\ E-mail: manasakumar94@gmail.com \\ Dr. U. B Mahadevaswamy \\ Sri Jayachamarajendra College of Engineering, Department of ECE, Mysuru, 570006, India \\ E-mail: ubms_sjce@yahoo.co.in
}

Received: 30 June 2017; Accepted: 22 September 2017; Published: 08 February 2018

\begin{abstract}
The healthcare monitoring system is very useful for the old age people, cardiac vascular endues and many others for observing vital parameters like blood pressure, heart rate, pulse rate, body temperature etc. The proposed work utilizes 8bit X-Mega2560 microcontroller with an application created for overseers and hospital to constantly watch the patient's parameters from their home, hospitals etc. The proposed system senses the vital parameters of the patients and sends an alert message to respective caretakers, through Wi-Fi which utilizes COAP conventions. These models are integrated to a simple arduino uno microcontroller to exhibit different functionalities. The system will reduce the cost, empowering the patients who are not able to consult the doctors for diagnosis and also minimize the patient's transportations. This system will bridge the gap between patient and doctor in real time.
\end{abstract}

Index Terms-Wi-Fi, COAP (Constrained application protocol), Monitoring, Arduino UNO microcontroller, vital parameters, LCD.

\section{INTRODUCTION}

Now a day's health is very important because everyone needs it at several points in their life time. There are many issues on health related cases throughout the year. It is very much essential to continuously monitor the one's health. Well-being is the most vital consideration for every single living being irrespective of their age and standards. The medical problems occur due to lack of knowledge regarding cleanliness, not knowing the maladies, self-medication, drug addiction, alcohol consumption etc. Due to these problems people suffer more and frequently visit hospital to check their health. The proposed system helps the patient continuously monitor their health condition at home and send the information regarding to doctor using android application. The most noteworthy feature of this system is that, the health condition of a patient can be made known to all concerned. The rest of the paper is organized as follows. In section II, a literature survey has been presented.
Motivation of a proposed system is discussed in section III. The problem statement is given in section IV and objectives of proposed work are stated in section $\mathrm{V}$. Section VI discusses the implementation of proposed work. The results are discussed in section VII, and the conclusion is given in section VIII.

\section{RELATED WORK}

Monitoring of the health condition of a patient under critical illness and conveying the monitored information to the care takers and concerned doctors is a major concern of this work. This section reviews the various technologies available for wireless communication, their merits and demerits. This section also reviews the different sensors to measure the vital sign parameters like blood pressure, heart rate and body temperature.

In [1], it implements the tele-monitoring system for continuous monitoring of chronic conditions such as $\mathrm{CHF}$ (chronic heart- failure) and alert physicians for any Signs and symptoms occurrence. This is not a battery powered system which is the main drawback.

In [2], a healthcare monitoring system is implemented through GSM based networks. On violation of vital parameters, automatically send the message to caretakers or doctor.

Paper [3] details design and implementations based on GSM enabled embedded system for monitoring the biomedical parameters like blood pressure and body temperature. The system uses GSM for communicating the abnormalities in the simulated bio-medical parameters.

Paper [4] explains about how to monitor the patient's health condition by introducing the WBAN system and cloud based computing.

Paper [5] describes to improve the efficiency of medical gadget. Based on IOT technology monitoring the patient's sign parameters which uses the different protocol and RFID to identify physiological conditions, UHRFID is used and must be implement to every patient to make this system local access only.

In [6], proposes a novel algorithm for BEC node and monitors the patient's health via WBAN server. 
Authors in [7], planned a mobile health application for fare observance and assessment, which is able to keep a track of daily personal health record of a user for blubber interference. The appliance can send alerts and messages regarding the user's diet program taking into consideration his physical activity.

In [8], the embedded microcontroller is connected to set of medical sensors and communication modules which check the patient health condition status. If the results are abnormal, embedded unit uses the patient's phone to transmit the patient's status to medical center. In this situation doctor will send medical advice to patient to save his hher life.

Paper [9] focuses on the measurement and monitoring various parameters of patient's body like heart rate, temperature, and blood pressure using web server and android application. Using an android app doctor can monitor the patient's condition, and patient's data will be stored on the web server. And doctor can access the patient's information whenever needed.

Paper [10] presents an IOT remote healthcare monitoring system that provides the patient's vital sign parameters (heart rate, ECG, blood pressure, oxygen saturation in blood level, etc.) through web browser. Implementation is based on CoAP protocol on Mozilla Firefox web browser and the manipulation of resources by CoAP methods.

Paper [11] gives the proper and efficient medical services to patients by connecting and collecting the required data information through health status monitors which would include patient's blood pressure, ECG and heart rate and sends an alert message to concerned doctor with his current status and full medical information.

In [12], using a specific sensor, the data will be captured and compared with a configurable threshold via microcontroller which is defined by a specialized doctor. In case of emergency a short message service (SMS) will be sent to the Doctor's mobile number along with the measured values through GSM module. Furthermore, the GPS provides the position information of the monitored person who is under surveillance all the time. This paper also demonstrates the feasibility of realizing a complete end to end smart health system responding to the real health system.

Paper [13] demonstrates the feasibility of using flexible, and user-friendly equipment to inform others when user needs an emergency response. And also presents a combination of mobile communication with data transmission through Wi-Fi.

In [14], improving ambulance transportation availability services when requests are made without having to call or wait for long time. This paper analyzed, designed and implemented a prototype to demonstration the operation of the system to show its effectiveness with respect to the current system.

Paper [15], presented the health monitoring using smart phone accessories. The major benefit to using this system is that the users do not have to carry an extra device while maintaining their health and safety. Additionally, to improved the accuracy of the ECG measurement.

Following are the drawbacks of the existing systems which the authors have learned through literature survey.

- Safety and security measures have not considered.

- Many of the authors use the GSM and GPS network to monitoring the patient's health.

\section{Motivation}

When a patient is in critical illness, timely monitoring of vital sign parameters and providing with the required treatment is very important. In many cases the patient may be alone, caretakers and concerned doctors are faraway for him. Under this condition the patient may reach a critical state or even die. In order to help such kind of people to draw the attention of concerned and provide with them the necessary treatment, the author's thought of developing a fully automated wearable and smart healthcare monitoring system.

\section{PRoblem Statement}

Medical facilities in rural areas are of major concerned due to lack of transportations, infrastructure facilities and non-availability of medical faculties. Hence to overcome these difficulties a smart real-time embedded based medical healthcare system has to be designed which continuously monitors the patient's health, alerts concerned persons over App for health degradations so that medication is possible to provide in stipulated time.

\section{OBJECTIVES}

The objective of a proposed work is to build up a healthcare monitoring system that provides assistance in case of emergency for the patients, old age people, cardiovascular suffer etc. for monitoring vital parameters. The system continuously acquires the patient data, process and sends information wirelessly to caretakers and concerned doctor, using CoAP protocol without any human interference. The main objectives of the proposed system are as follows.

- To monitor the patient's condition in real-time and provide an effective and needful medical service alert at the earliest.

- To design emergency medical assistance system (EMAS), and provide gateway using CoAP for secured communication.

- To monitor the patient's health status through an android app.

- To create an RTOS based embedded design for the proposed system.

\section{IMPLEMENTATION}

The main aim of a proposed system is to cover end to 
end smart healthcare application system. It consists of LCD, microcontroller and sensors, etc. as shown in fig.1. The system block diagram is divided into two units first unit is controlling and communication which is done using X-Mega2560, 16 MIPS processing speed, 8bit controller, 10bit ADC, 3UART, SPI and GPIO.

The various components required for implementation of a proposed system are described in following subsection.

\section{A. Arduino Microcontroller}

In this proposed system we have used arduino X-Mega 2560 microcontroller board, which is based on X-Mega 2560 microcontroller. All models are controlled by microcontroller.

\section{B. Wi-Fi}

ESP8266 node MCU Wi-Fi communicate at 100Kbps speed using $2.4 \mathrm{GHz}$ frequency, user can get access to the status information about vital parameters by using specific android app install in the smart phone.

\section{C. $L C D$}

A LCD is a tool used for visual display of the output and it follows the properties of light modulation for its display. A LCD is required in this project to display various messages to user and thus making the device convenient. The various types of messages include a bed wet detected or alert due to increase in temperature or heart rate.

\section{D. $L M 35$}

LM35 is an analog sensor is mainly used to measure temperature variation in patient's body, LM35 sensor is a RTD type which gives the output as according to variation in temperature resistance. Output voltage of the sensor will vary from 0.1 to $5 \mathrm{~V}$. LM35 sensor is connected to ADC channel of microcontroller for the best conversion of voltage into temperature.

\section{E. Pulse Oximetry}

Fingertip sensor based BPM estimation with the help of infrared transmitter and a photo transistor arranged side by side by using optical type TCRT1000 sensor. This sensor divided into four stages first stage consist of TCRT with two transistor forming as a voltage divider and current limiting for photo diode, $10 \mathrm{k} \Omega$ resistor is connected to $\mathrm{V}_{\mathrm{cc}}$ and collector, emitter is connected to ground. When IR light reflects back to photo transistor they act as a barrier breaks, causing the electron to move from $\mathrm{P}$ to N. when transistor turn on, output at V Sensor changes its waveform in periodic attributed formation for physical variation of reflected IR.

\section{F. Blood Pressure}

Systolic and diastolic pressures can be measured by auto inflate BP unit. This consists of cuff, air pump and solenoid d pressure valve and $50 \mathrm{Kba}$ pressure sensor. When system is activated it starts pumping air into cuff through air pump. Which must not be more than
$161 \mathrm{mmHg}$ of systolic and $91 \mathrm{mmHg}$ of diastolic pressure. When systolic pulse is obtained at $121 \mathrm{mmHg}$ and diastolic pulse obtained at $81 \mathrm{mmHg}$ pump will be stopped after that air will be deflected.

\section{G. Bed Wet Detection}

Bed wet detection detects the saline contain in water. This sensor is made up of two electrodes, one is a copper wire another one is nick chrome wire with an j-fit transistor, nick chrome connected to base of transistor, copper is connected to $\mathrm{V}_{\mathrm{cc}}$ through a $10 \mathrm{k} \Omega$ resistor, collector of these transistor is directly connected to $\mathrm{V}_{\mathrm{cc}}$, emitter is connected to ground via $10 \mathrm{k} \Omega$ resistor a output is taken for analog to digital conversion.

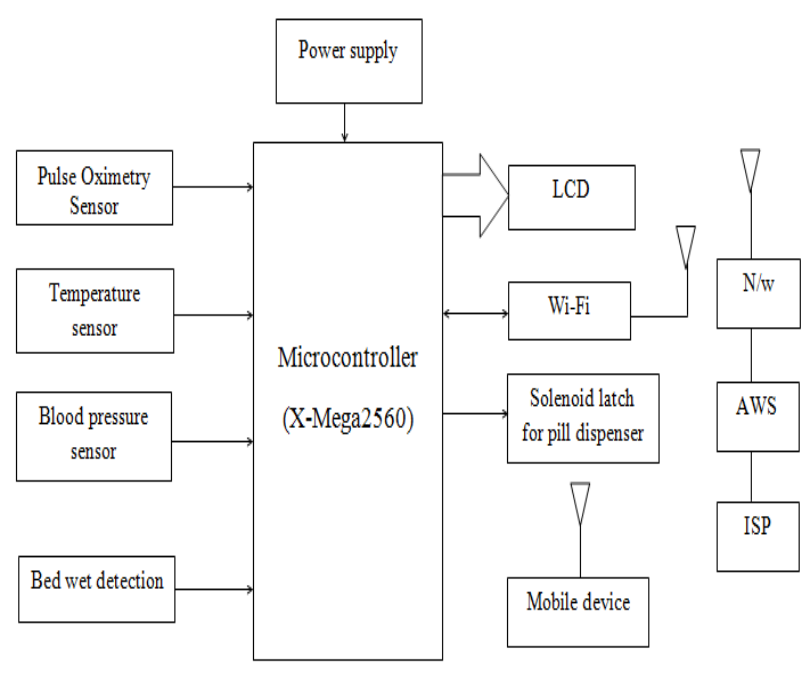

Fig.1. Block diagram of a Proposed System.

\section{H. Pill Dispenser}

A $12 \mathrm{~V}$ latch type solenoid is used to stimulate the operation of pill dispenser. Solenoid is an analog electromagnetic type device. Microcontroller cannot drive the solenoid directly because microcontroller is a digital device, solenoid needs $12 \mathrm{~V}$ at $120 \mathrm{~mA}$ current to drive. Hence to overcome these problems a L293D Hbridge is used to drive the microcontroller, when user press dispenser button, microcontroller sends a high signal to driver and derive drives the solenoid latch.

The flowchart of a proposed system is shown in Fig 2.

\section{RESULTS AND DISCUSSION}

The proposed system requires low-bandwidth and it can be battery-powered. Fig. 3 shows the complete module setup. Here we develop the prototype of monitoring the various vital parameters with the help of microcontroller and an alert message through android app. This prototype streams the live sense data onto vital parameters of the patient. 


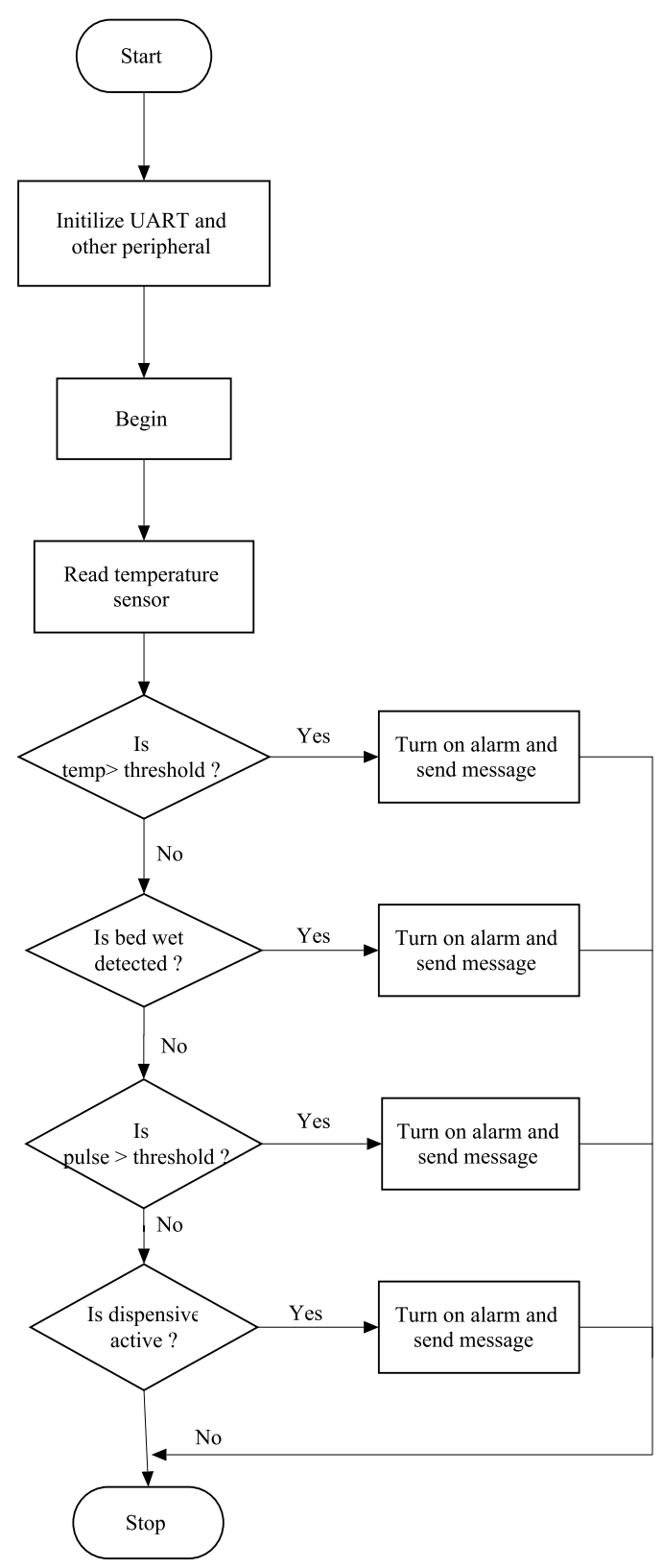

Fig.2. Flo wchart of a Proposed System.

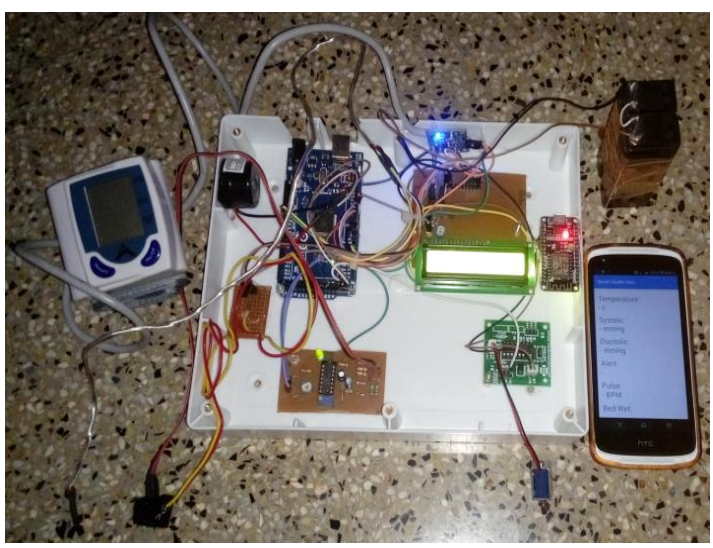

Fig.3. Complete Module Setup.

LCD displays the operating condition of a device and also indicates its status. The following snapshots are taken from system LCD and can be used in result analysis.
Bed wet detection: For the detection of bed wet two probes are inserted into pad. The probes measure the conductivity. In the presence of wetness the conductivity will be more than when it is dry. In case of bed wet detection the information is displayed on LCD and an alert message is also sent as shown in Fig. 4.

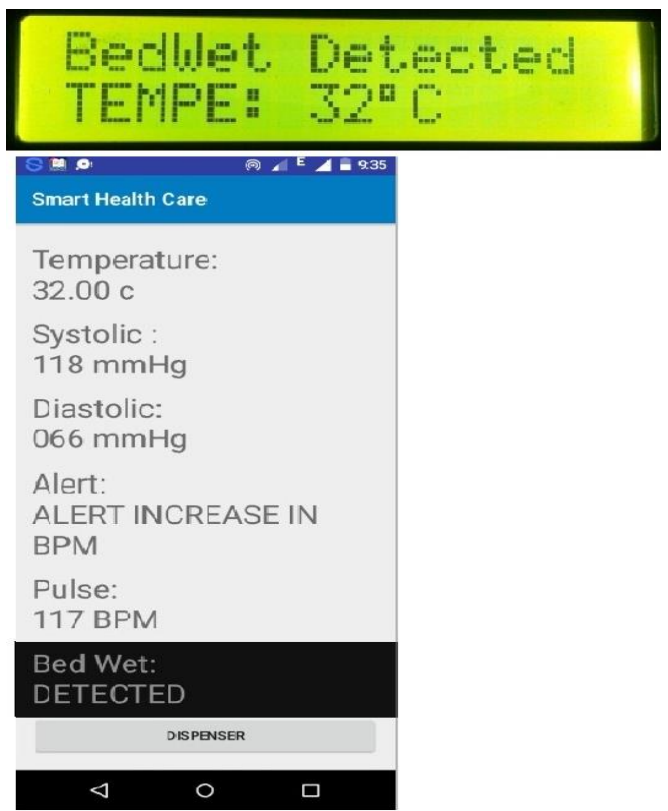

Fig.4. Bed Wet Detection is displayed on LCD with Respect to App to Monitor.

Temperature detection: Temperature detection is done by using a temperature sensor (LM35). Which is placed in between armpit to detect the body temperature and the measured data is displayed on LCD and a message is sent as shown in Fig.5. If the temperature crosses its threshold value then an alert message is sent to mobile app.

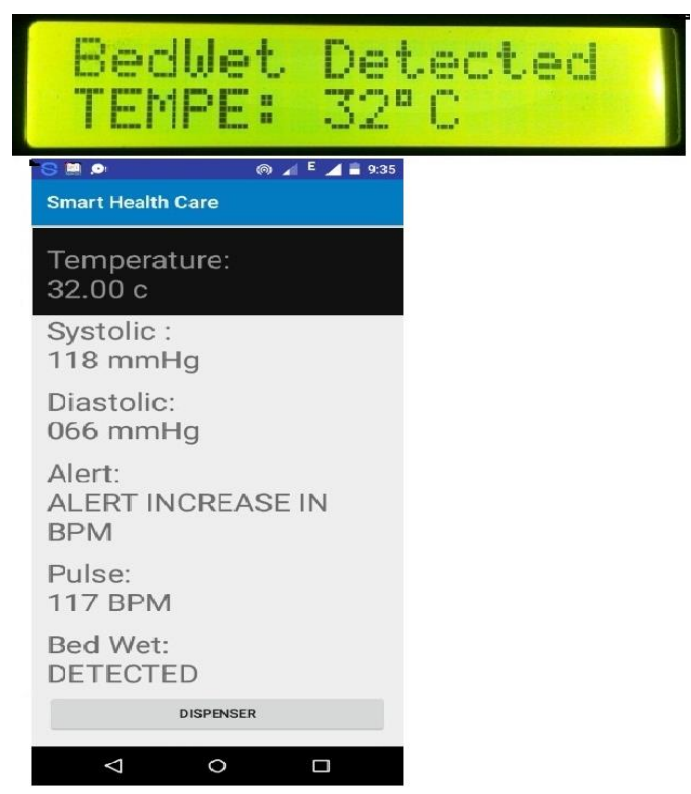

Fig.5. Temperature Reading on LCD and App.

Blood pressure: For the measure of blood pressure a blood pressure unit is used, which is inserted into the 
hand, blood pressure of both systolic and diastolic pressures is measured by the BP unit that are displayed in LCD and also sent a message to mobile app as shown in fig.6. If any variation in the blood pressure is found then an alert message is sent to an android app.

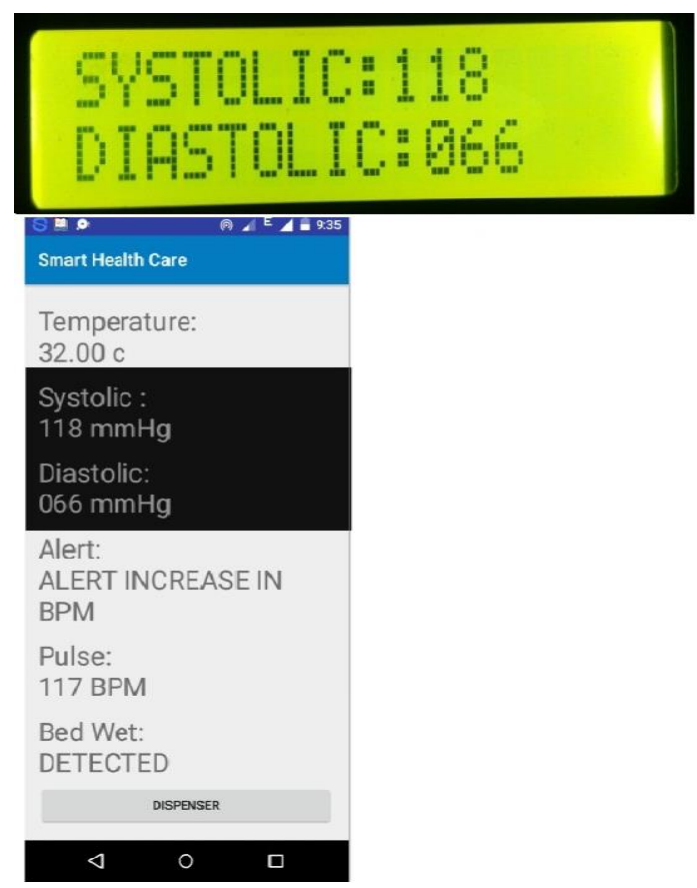

Fig.6. Blood Pressures Reading on LCD and App.

Pulse rate detection: Monitoring the pulse rate is done by using the sensor which is fixed to the index finger. An alert message is displayed on LCD as shown in fig.7. Fig. 8 shows the monitored of all vital parameters are displayed on LCD with respect to app. Table 1 shows the comparison between proposed system and exiting system.

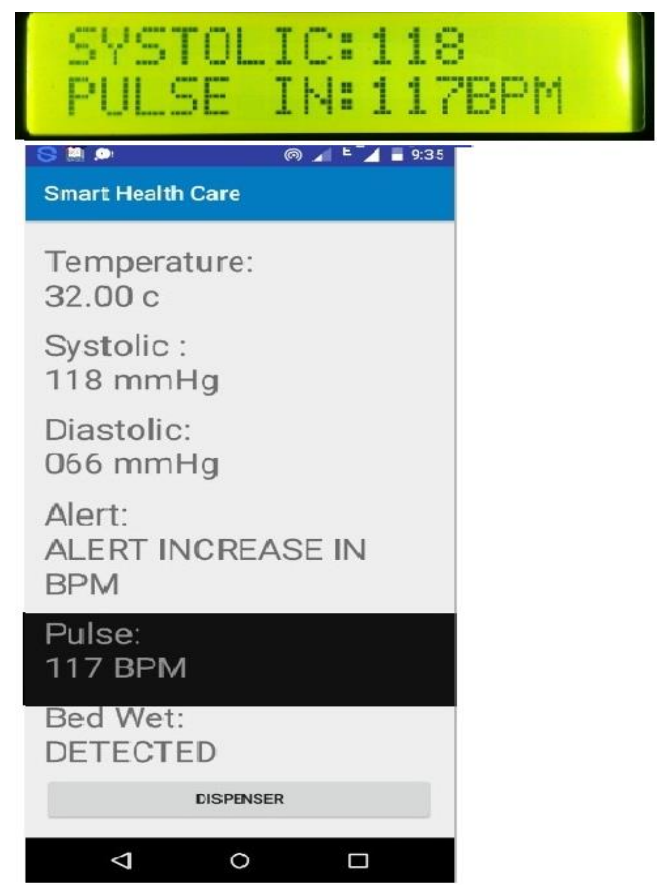

Fig.7. Indication of Bed Wet Detection and Increased in Pulse Rate On LCD and App.
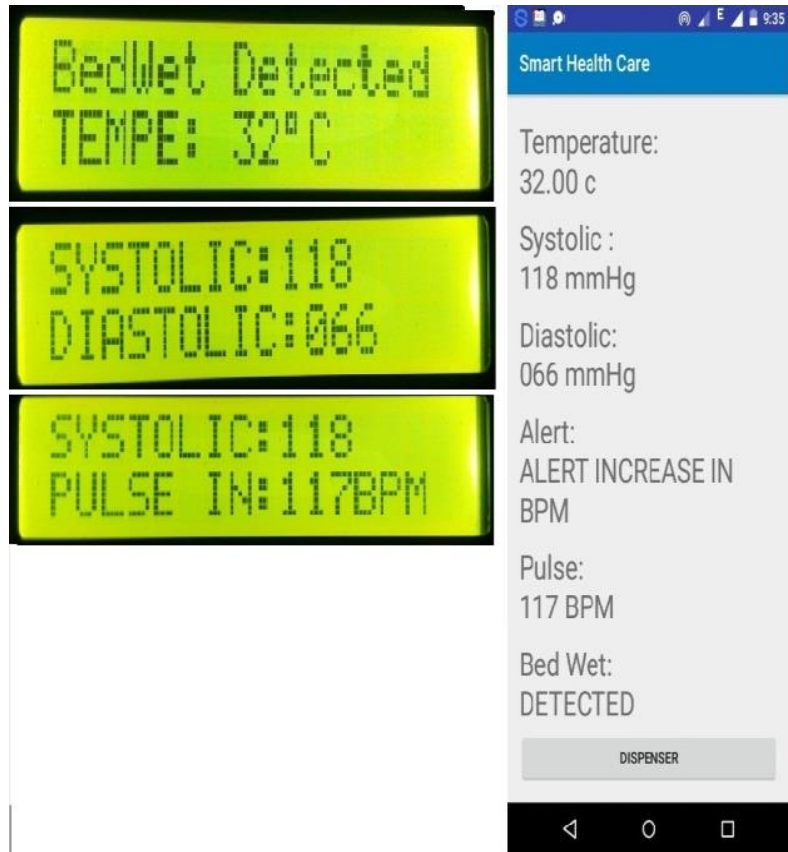

Fig.8. Measurement and Display of all Vital Parameters on LCD and App.

Table 1 shows the comparison between proposed system and exiting system. Tables 2, 3, 4 and 5 will present the vital sign measurement like heart rate, body temperature and blood pressure of various patients.

Table 1. Comparison between Proposed System and Exiting System

\begin{tabular}{|c|c|c|}
\hline Parameters & Existing design & Proposed design \\
\hline $\begin{array}{l}\text { Communications } \\
\text { and cost }\end{array}$ & $\begin{array}{c}\text { Reliable in } \\
\text { communication and } \\
\text { cost }[12]\end{array}$ & $\begin{array}{l}\text { Real time and } \\
\text { minimal band width }\end{array}$ \\
\hline Security & less secured [4] & $\begin{array}{l}\text { Highly secured due } \\
\text { to } \mathrm{QOS}_{2}\end{array}$ \\
\hline Could computing & $\begin{array}{l}\text { Support only } \\
\text { desktop [7] }\end{array}$ & $\begin{array}{c}\text { Support AWS using } \\
\text { CoAP }\end{array}$ \\
\hline GPS, GSM & $\begin{array}{c}\text { Based location } \\
\text { identification, SMS } \\
\text { sending [5] }\end{array}$ & $\begin{array}{c}\text { Due to specific ID, } \\
\text { no need GPS }\end{array}$ \\
\hline Monitoring & $\begin{array}{l}\text { Quiz real time } \\
\text { (SMS only) [5] }\end{array}$ & Real time \\
\hline Display type & Text [8] & GUI \\
\hline $\begin{array}{l}\text { Transmission } \\
\text { requirement }\end{array}$ & $\begin{array}{l}\text { Only when network } \\
\text { connection exits [1] }\end{array}$ & $\begin{array}{l}\text { All time due to } \\
\qquad \mathrm{Wi}-\mathrm{Fi}\end{array}$ \\
\hline Data size & Few bytes [6] & Up-to $1 \mathrm{~Kb}$ \\
\hline Sensor monitoring & Continuous [3] & Continuous \\
\hline
\end{tabular}


Table 2. Heart Rate Measurement

\begin{tabular}{|c|c|c|c|c|c|}
\hline \multirow[b]{2}{*}{$\begin{array}{l}\text { SI. } \\
\text { NO }\end{array}$} & \multirow[b]{2}{*}{$\begin{array}{c}\text { Patient } \\
\text { name }\end{array}$} & \multirow[b]{2}{*}{$\begin{array}{c}\text { Patient } \\
\text { age }\end{array}$} & \multicolumn{2}{|c|}{ Heart rate (BPM) } & \multirow[b]{2}{*}{$\begin{array}{l}{ }^{1} \% \\
\text { Error }\end{array}$} \\
\hline & & & $\begin{array}{l}\text { As per the } \\
\text { physician }\end{array}$ & $\begin{array}{l}\text { As per } \\
\text { the } \\
\text { system }\end{array}$ & \\
\hline 1 & XXXX1 & 23 & 91 & 90 & +1.1 \\
\hline 2 & $\mathrm{XXXX} 2$ & 26 & 89 & 87 & +2.2 \\
\hline 3 & XXXX3 & 32 & 90 & 88 & +2.2 \\
\hline 4 & XXXX4 & 35 & 77 & 76 & +1.3 \\
\hline 5 & XXXX5 & 37 & 97 & 96 & +1.0 \\
\hline 6 & XXXX6 & 38 & 87 & 88 & -1.1 \\
\hline 7 & XXXX7 & 42 & 90 & 91 & -1.1 \\
\hline 8 & XXXX8 & 43 & 90 & 89 & +1.1 \\
\hline 9 & XXXX9 & 49 & 77 & 75 & +2.6 \\
\hline 10 & $\mathrm{XXX10}$ & 54 & 92 & 95 & -3.3 \\
\hline 11 & XXX11 & 56 & 101 & 100 & +1.0 \\
\hline 12 & XXX12 & 62 & 91 & 93 & -2.2 \\
\hline 13 & XXX13 & 65 & 90 & 91 & -1.1 \\
\hline 14 & XXX14 & 70 & 71 & 73 & -2.8 \\
\hline 15 & XXX15 & 76 & 77 & 75 & -2.6 \\
\hline 16 & XXX16 & 80 & 107 & 110 & -2.8 \\
\hline
\end{tabular}

$$
{ }^{1} \% \text { Error }=\frac{X-Y}{X} \times 100
$$

Where:

$\mathrm{X}=$ Heart rate recorded by physician

$\mathrm{Y}=$ Heart rate recorded by the system

Table 2 lists the readings of heart rate measurement of patients belong into a wide range of age groups note that the error is $\pm 3.3 \%$ which is in tolerable limits.

Table 3. Body Temperature Measurement

\begin{tabular}{|c|c|c|c|c|c|}
\hline \multirow{2}{*}{$\begin{array}{l}\text { SI. } \\
\mathrm{N} \\
\mathrm{O}\end{array}$} & \multirow{2}{*}{$\begin{array}{l}\text { Patient } \\
\text { name }\end{array}$} & \multirow{2}{*}{$\begin{array}{c}\text { Patient } \\
\text { age }\end{array}$} & \multicolumn{2}{|c|}{$\begin{array}{l}\text { Body temperature } \\
\left({ }^{0} \mathrm{c}\right)\end{array}$} & \multirow{2}{*}{$\begin{array}{l}2 \% \\
\text { Error }\end{array}$} \\
\hline & & & $\begin{array}{l}\text { As per the } \\
\text { physician }\end{array}$ & $\begin{array}{l}\text { As per } \\
\text { the } \\
\text { system }\end{array}$ & \\
\hline 1 & $\mathrm{XXXX1}$ & 23 & 35.2 & 36 & +2.8 \\
\hline 2 & $\mathrm{XXXX2}$ & 26 & 38.5 & 38 & +1.3 \\
\hline 3 & XXXX3 & 32 & 38.6 & 38 & +1.6 \\
\hline 4 & $\mathrm{XXXX4}$ & 35 & 36.5 & 37 & -1.4 \\
\hline 5 & XXXX5 & 37 & 36.3 & 37 & -1.9 \\
\hline 6 & XXXX6 & 38 & 37.5 & 38 & -1.3 \\
\hline 7 & $\mathrm{XXXX7}$ & 42 & 37.5 & 36 & -1.4 \\
\hline 8 & XXXX8 & 43 & 37.5 & 37 & +1.3 \\
\hline 9 & $\mathrm{XXXX9}$ & 49 & 35.2 & 36 & +2.3 \\
\hline 10 & XXX10 & 54 & 35.5 & 36 & -1.4 \\
\hline 11 & XXX11 & 56 & 36.3 & 37 & -1.9 \\
\hline 12 & $\mathrm{XXX12}$ & 62 & 35.6 & 36 & -1.1 \\
\hline 13 & XXX13 & 65 & 36.5 & 36 & +1.4 \\
\hline 14 & XXX14 & 70 & 38 & 39 & -2.6 \\
\hline 15 & XXX15 & 76 & 37.5 & 38 & -0.01 \\
\hline 16 & XXX16 & 80 & 37 & 38 & -2.7 \\
\hline
\end{tabular}

$$
2 \% \text { Error }=\frac{\mathrm{A}-\mathrm{B}}{\mathrm{A}} \times 100
$$

Where:

$\mathrm{A}=$ Body temperature recorded by physician

$\mathrm{B}=$ Body temperature recorded by the system

From table 3, it clear that the measured body temperature of patients under various age groups using the proposed system deviates with a percentage error of $\pm 2.8 \%$ with respect to conventional approach. This error is in tolerable limits.

\begin{tabular}{|c|c|c|c|c|c|}
\hline \multirow{2}{*}{$\begin{array}{l}\text { SI. } \\
\text { NO }\end{array}$} & \multirow{2}{*}{$\begin{array}{c}\text { Patient } \\
\text { name }\end{array}$} & \multirow{2}{*}{$\begin{array}{l}\text { Patient } \\
\text { age }\end{array}$} & \multicolumn{2}{|c|}{$\begin{array}{l}\text { Blood pressure for } \\
\text { systolic }(\mathrm{mmHg})\end{array}$} & \multirow{2}{*}{$\begin{array}{l}{ }^{3} \% \\
\text { Error }\end{array}$} \\
\hline & & & $\begin{array}{l}\text { As per the } \\
\text { physician }\end{array}$ & $\begin{array}{l}\text { As per } \\
\text { the } \\
\text { system }\end{array}$ & \\
\hline 1 & XXXX1 & 23 & 120 & 123 & -2.5 \\
\hline 2 & $\mathrm{XXXX2}$ & 26 & 158 & 156 & +1.3 \\
\hline 3 & XXXX3 & 32 & 118 & 120 & -1.7 \\
\hline 4 & XXXX4 & 35 & 119 & 119 & 0.0 \\
\hline 5 & XXXX5 & 37 & 130 & 127 & +2.3 \\
\hline 6 & XXXX6 & 38 & 128 & 130 & -1.6 \\
\hline 7 & XXXX7 & 42 & 139 & 140 & -0.7 \\
\hline 8 & XXXX8 & 43 & 125 & 124 & +0.8 \\
\hline 9 & XXXX9 & 49 & 113 & 115 & -1.8 \\
\hline 10 & XXX10 & 54 & 118 & 120 & -1.7 \\
\hline 11 & XXX11 & 56 & 140 & 138 & +1.4 \\
\hline 12 & XXX12 & 62 & 130 & 129 & +0.8 \\
\hline 13 & XXX13 & 65 & 128 & 130 & -1.6 \\
\hline 14 & XXX14 & 70 & 138 & 140 & -1.4 \\
\hline 15 & XXX15 & 76 & 140 & 138 & +1.4 \\
\hline 16 & XXX16 & 80 & 156 & 156 & 0.0 \\
\hline
\end{tabular}

Table 4. Systolic of Blood Pressure Measurement

\begin{tabular}{|c|c|c|c|c|c|}
\hline \multirow[t]{2}{*}{ SI.NO } & \multirow{2}{*}{$\begin{array}{c}\text { Patient } \\
\text { name }\end{array}$} & \multirow{2}{*}{$\begin{array}{l}\text { Patient } \\
\text { age }\end{array}$} & \multicolumn{2}{|c|}{$\begin{array}{l}\text { Blood pressure for } \\
\text { diastolic }(\mathrm{mmHg})\end{array}$} & \multirow{2}{*}{$\begin{array}{l}{ }^{3} \% \\
\text { Error }\end{array}$} \\
\hline & & & $\begin{array}{c}\text { As per } \\
\text { the } \\
\text { physician }\end{array}$ & $\begin{array}{l}\text { As per } \\
\text { the } \\
\text { system }\end{array}$ & \\
\hline 1 & XXXX1 & 23 & 83 & 84 & -1.2 \\
\hline 2 & XXXX2 & 26 & 96 & 97 & -1.0 \\
\hline 3 & XXXX3 & 32 & 86 & 87 & -1.1 \\
\hline 4 & XXXX4 & 35 & 88 & 90 & -2.5 \\
\hline 5 & XXXX5 & 37 & 90 & 93 & -3.3 \\
\hline 6 & XXXX6 & 38 & 82 & 84 & -2.4 \\
\hline 7 & XXXX7 & 42 & 95 & 92 & +3.1 \\
\hline 8 & XXXX8 & 43 & 85 & 85 & 0.0 \\
\hline 9 & XXXX9 & 49 & 77 & 76 & +1.3 \\
\hline 10 & XXX10 & 54 & 87 & 89 & -2.3 \\
\hline 11 & XXX11 & 56 & 100 & 97 & +3.0 \\
\hline 12 & XXX12 & 62 & 90 & 89 & +1.1 \\
\hline 13 & XXX13 & 65 & 89 & 92 & -3.4 \\
\hline 14 & XXX14 & 70 & 95 & 98 & -3.2 \\
\hline 15 & XXX15 & 76 & 100 & 101 & -1.0 \\
\hline 16 & XXX16 & 80 & 101 & 102 & -0.9 \\
\hline
\end{tabular}

Table 5. Diastolic of Blood Pressure Measurement 
The table 4 and 5 shows the measurement of both systolic and diastolic blood pressure. Observe from above table that the errors in the measurement of systolic and diastolic blood pressures respectively are $\pm 2.5 \%$ and $\pm 3.3 \%$ which are in the tolerable limits.

$$
3 \% \text { Error }=\frac{\mathrm{P}-\mathrm{Q}}{\mathrm{P}} \times 100
$$

Where:

$\mathrm{P}=$ Systolic and diastolic blood pressures as recorded by physician

$\mathrm{Q}=$ Systolic and diastolic blood pressures as recorded by the system

\section{CONCULSION AND FUTURE WORK}

The proposed system provides low power consumption, low complexity and highly portable for healthcare monitoring of patient's and it can reduce the need of utilization of expensive facilities. The doctor can easily access the patient's information at any time and in anywhere with the help of android application. This innovation enhances the life style of the people.

In future, we can develop a long range remote data base of all the patients of any hospital and these health parameters can be monitored continuously, and also the information is uploaded to the hospital server. These servers keep the information of patients in the data base, and doctors can have the access of patient's history, when any further consultancy happens with the doctor.

\section{ACKNOWLEDGMENT}

The authors thank the principal, professor, all technical staff of electronics and communication department of Sri jayachamarajendra College of Engineering, Mysuru, Karnataka, India for their support in completing this work.

\section{REFERENCES}

[1] Daniel Aranki, Student Member, IEEE, Gregorij Kurillo, Posu Yan, David M. Liebovitz, and Ruzena Bajcsy, Life Fellow, IEEE "Real-Time Tele-Monitoring of Patients with Chronic Heart-Failure Using a Smartphone: Lessons Learned", IEEE journal, july-september 2016, vol.7, no.3. "doi:10.1109/TAFFC.2016.2554118"

[2] Nur Hidayah Binti Abu Bakar, Khaizuran Abdullah and Md Rafiqul Islam, "Wireless Smart Health Monitoring System Via Mobile Phone" IEEE, august 2016, vol. 978, no. 1, ppl.5090-2427. "doi:10.1109/ICCCE.2016..55"

[3] Sudhindra.F, Annarao.S.J, Vani.R.M and P.V. Hunagund, "A GSM Enabled Embedded System for Blood Pressure \& Body Temperature Monitoring" IJAREEIE, January 2014, vol. 3, Issue 1.

[4] Jetendra Joshi, Divya Kurian, Satyam Bhasin Prakhar Awasthi, Sibeli Mukherjee, Sanya Mittal, and Shribbha Sharma, "Health Monitoring Using Wearable Sensor and Cloud Computing”, IEEE, April 2016, vol. 978, No. 1, ppl. 5090-3572. "doi:10.1109/CRC.2016.031"

[5] Luca Catarinucci, Danilo de Donno, Luca Mainetti, Luca Palano, Luigi Patrono, Maria Laura Stefanizzi, and
Luciano Tarricone "An IoT-Aware Architecture for Smart Healthcare Systems" IEEE internet of things journal, december 2015, vol. 2, no. 6 . "doi:10.1109/JIOT.2015.2417684"

[6] M. A. Hamid, M. M. Alam, M. S. Islam, C. S. Hong, and S. Lee, "Fair data collection in wireless sensor networks: analysis and protocol", Annals of Telecommunications, vol. 65, no.7-8, pp. 433-446, 2010.

[7] Nabil Ali Alrajeh, Jaime Lloret, and Alejandro Canovas,"A Framework for obesity control using a wireless Body sensor network", International jouranl of distribution sensor networks Volume 2014, pp. 2-3, July 2014.

[8] Kasim M. Al-Aubidy, Ahmad M. Derbas. \& Abdullah W. Al-Mutairi, "Real-Time Patient Health Monitoring and Alarming Using Wireless-Sensor Network", IEEE, June 2016, Vol.978, No.1, ppl.5090-1291. "doi:10.1109/SSD.2016.7473672"

[9] Maradugu Anil Kumar, Y.Ravi Sekhar, "Android Based Health Care Monitoring System”, IEEE $2^{\text {nd }}$ international conference, march 2015, vol.978, no.1, ppl.4799-6818. "doi:10.1109/ICIIECS.2015.7192877"

[10] Dejana Ugrenovic, Gordana Gardasevic, "CoAP protocol for web based monitoring in IOT healthcare applications", IEEE, May 2015, vol. 978, No. 1, ppl. 5090-0055. "doi:10.1109/TELFOR.2015.7377418"

[11] Punit Gupta, Deepika Agrawal, Jasmeet Chhabra, Pulkit Kumar Dhir "IoT based Smart HealthCare Kit", IEEE, January 2016, vol. 978, no. 1, ppl. 5090-0082. “doi; 10.1109/ICCTICT.2016.7514585"

[12] Kahtan Aziz, Saed Tarapiah, Salah Haj Ismail, "Smart Real-Time Healthcare Monitoring and Tracking System using GSM/GPS Technologies", IEEE, July 2016, Vol. 978, No. 1, ppl. 4673-9584. "doi: 10.1109/ICBDSC.2016.7460394"

[13] Eriola J. Shanko, Michalis G. Papoutsidakis, "Real Time Health Monitoring and WirelessTransmission: A $\mu$ Controller Application to Improve Human Medical Needs", IEEE, January 2013, vol. 978, No. 1, ppl.47992373. "doi: 10.1109/EHB.2013.6707254"

[14] Bassey Isong, Nosipho Dladlu, Tsholofelo Magogodi,"Mobile-Based Medical Emergency Ambulance Scheduling System", International Journal of Computer Network and Information Security(IJCNIS), Vol.8, No.11, pp.14-22, 2016.”doi: 10.5815/ijcnis.2016.11.02"

[15] Md. Shaad Mahmud , Honggang Wang, A.M. Esfar-EAlam, Hua Fang, "A Wireless Health Monitoring System Using Mobile Phone Accessories" IEEE Internet of Things Journal. “doi: 10.1109/JIOT.2016.2645125”

\section{Authors' Profiles}

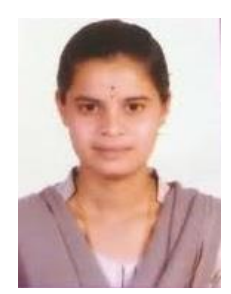

Manasa received her $\mathrm{BE}$ degree in electronics and communication from VTU Belgaum, Karnataka, India in the year 2015. She is pursuing M.Tech in VLSI design and embedded systems at Sri Jayachamarajendra College of Engineering, mysuru, Karnataka, India. 
Dr. U. B. Mahadevaswamy has completed his BE degree in electronics and communication in the year 1988 from University of Mysore, M.Tech in industrial electronics in the year 1995 from Mangalore University and obtained Phd in electronics from University of Mysore in the year 2013. $\mathrm{He}$ is presently working as Associate professor in the department of electronics and communication of Sri Jayachamarajendra College of Engineering, Mysuru, Karnataka, India. He has authored several textbooks and published many technical and research papers in international journals and conferences. His research interest includes the topics; wireless sensors networks, VLSI design, embedded systems and digital signal processing.

How to cite this paper: Manasa, U. B Mahadevaswamy,"Wireless Wearable Smart Healthcare Monitoring using Android", International Journal of Computer Network and Information Security(IJCNIS), Vol.10, No.2, pp.12-19, 2018.DOI: $10.5815 /$ ijcnis.2018.02.02 